\title{
Time for Elderly Rehabilitation and Nursing Care Center in the Country
}

\author{
Bhattarai M D \\ Medical Education Unit, National Academy of Medical Sciences, Bir Hospital, Kathmandu, Nepal
}

The population demography and socio-economic conditions in Nepal are changing, as in other parts of the world. With the increasing longevity of the population, there is an increased proportion of people of the older age group. Globalization and migration of younger people have lead to the decreasing trend of available family support for the older population living inside the country. Moreover, the traditional joint-family system is changing into the nuclear family. Thus it is now becoming frequent for older people to be staying alone at home.

Aristotle had said long back "Man is a social animal". So, as long as people are active, they would like to remain in their own social circles and continue their activities. The problem arises when people are unable to look after themselves due to the many health problems, especially the inevitable consequences of old age. It is not possible for the general public to manage such conditions. The hospitals are made for management of acute conditions. To care for such people who are unable to look after themselves but who do not require to be hospitalized, the concept of Nursing Homes has developed in the industrialized countries. There is now an obvious need for a similar service in our country. The term Nursing Home in our country is used for private hospitals and there are other old people's centers providing support and/or shelter to the elderly people. To be clear in the functions of different centers, the appropriate term in this region could be "Elderly Rehabilitation and Nursing Care Centers" (ERNCC).

In the industrialized countries like the US, when people are unable to take care of themselves, they usually live in Nursing Homes; otherwise they live in their homes or in assisted living facilities. While the number of
Americans living in Nursing Homes for extended periods has fallen steadily over the past decade as an increasing proportion of older individuals remain in their homes or in assisted living facilities, the number receiving shortterm Nursing Home care has risen dramatically ${ }^{1}$.In 2008, approximately 1.4 million people lived in Nursing Homes at any given time. However, over the course of the year, over 3.25 million people spent time in a skilled nursing facility. ${ }^{2}$ Of the people in Nursing Homes in the US in 2008, $16.2 \%$ were between the ages of 65 and $74,33.0 \%$ between 75 and $84,32.0 \%$ between 85 and 94 , and $5.2 \%$ were 95 years of age or older. ${ }^{2}$ In Nepal, the proportion of people in the age-group 75 years and above had increased by $35 \%$ from the year 1991 to $2001^{3}$. The reports of the 2011 census are awaited. However, the proportion of the ageing population is increasing in Nepal and such population may require rehabilitation care in ERNCC (called Nursing Home in the industrialized countries) from time to time apart from the treatment care for acute conditions in the hospitals.

The acutely sick persons need to be admitted in the hospitals for management. Once there is no need for active treatment but the persons are still unable to take of themselves, they can be admitted to the ERNCC. In the ERNCC people can be admitted on a daily charge basis, as per the service requirements when they are unable to take care of themselves. Once they are able to move and take care of themselves, they would go back to their homes amongst their family and/or social members. If they require hospital treatment, they would have to be referred to the hospitals. The service of internists and other doctors, nurses, physiotherapists, and other support manpower will be required in the ERNCC. Consultation service of different specialty doctors will need to be managed similarly.

correspondence:

Dr. Madhur Dev Bhattarai

Medical Education Unit,

National Academy of Medical Sciences, Bir Hospital

Email: mdb@ntc.net.np 
There are many potential advantages of the ERNCC. It will solve a major concern of all people regarding what they will do if they become invalid in old age. People abroad can get the service of the ERNCC to take care of their parents when they become unable to look after themselves. Such ERNCC can also be developed for the rehabilitation after stroke to mobilize the patients and make them independent. The ERNCC could be training venues for doctors, nurses and other paramedical personnel, generating income for the center ERNCC could also particularly be useful as venues for Geriatric Medicine specialization training courses after Internal Medicine, as in other parts of the world. The academic activities will as a whole systematize the care of the elderly people benefitting the center as well.

\section{REFERENCES}

1. Gillick MR, Yurkofsky M, Schmader KE, Sokol HN. Medical care of the nursing home patient in the United States. UpToDate, 2011:19.1

2. Centers for Medicare and Medicaid Services. Nursing Home Data Compendium 2009. Washington: Centers for Medicare and Medicaid Services; 2009.
For initiation of such ERNCC, arrangement could be made to provide subsidized and tax-free support for land, ambulances and other vehicles from the government. Business houses and philanthropists can donate funds for support. It would be an important area to consider for support and development for the Non-Resident Nepalese (NRN), as ERNCC will take care of older people living inside the country. ERNCC have the potential to get other international support as well. Different prayer-groups and social workers can come to contribute. It can generate part-time work for people from different sectors. Different types of benefits are provided by the state regulations. ${ }^{4}$ In Nepal, the government does provide some allowance and health benefits to the old people. The time seems to be ripe to initiate the services of ERNCC in the country for the rehabilitation and support of the elderly population when they cannot take care of themselves.
3. Central Bureau of Statistics. Statistical Year Book of Nepal 2005. 10th Ed. Kathmandu: Central Bureau of Statistics; 2005.P. 5-11.

4. Mathur JS. Preventive and Social Medicine - A comprehensive Textbook. New Delhi: CBS Publishers and Distributors; 2007.P.120-1. 